\title{
Calculation of the power of anterior chamber implants
}

Jose R Villada, Palaniswamy Sunder Raj, Tayo Akingbehin

\begin{abstract}
Ninety seven eyes with anterior chamber implants and a best corrected visual acuity of at least 6/12 were studied, firstly, to compare the predictive accuracies of the commonly used formulas for intraocular lens (IOL) power calculation and, secondly, to determine the effect of optimising the ' $A$ ' constant on the predictive accuracies of the empirical SandersRetzlaff-Kraff (SRK) formulas. The accuracies of the empirical formulas (SRK and SRK II) were generally similar to those of the theoretical formulas (Binkhorst II and Colenbrander-Hoffer). However the original SRK formula was more accurate than the two theoretical formulas in long eyes and in all eyes overall. Optimisation of the ' $A$ ' constants did not improve the predictive accuracy of the empirical SRK formulas.
\end{abstract}

Several formulas are available for calculating intraocular lens (IOL) power. Theoretical ${ }^{1-3}$ formulas were used in the initial stages followed by the development of more accurate empiri$\mathrm{Cal}^{4-7}$ formulas. The two commonly used theoretical formulas are the Binkhorst $\mathrm{II}^{8}$ and Colenbrander-Hoffer ${ }^{9}$ but the Sanders-RetzlaffKraff or SRK regression formula ${ }^{7}$ is presently the most commonly used IOL power calculation formula and this has recently been modified (SRK II) ${ }^{10}$ to take into account the non-linear relationship between axial length and IOL power. The predictive accuracy of the newly described SRK II formula was better than the original SRK formula in posterior chamber IOLs. ${ }^{1011}$ In anterior chamber IOLs, however, the SRK II formula was found to be less accurate than the original SRK formula and both of them were less accurate than the Binkhorst II formula. ${ }^{12}$ A literature search revealed only a limited number of studies on the performance of various IOL power calculation formulas in anterior chamber IOLs.

The use of optimised, rather than manufacturer recommended, constants has been reported to improve the predictive accuracy of the empirical SRK and SRK II formulas in posterior chamber lens implantation. ${ }^{1011} 13-17$ Comparable information is not available for anterior chamber IOLs. This study was carried out, firstly, to compare the predictive accuracies of the commonly used IOL power calculation formulas and, secondly, to determine the effect of optimising the ' $\mathrm{A}$ ' constant on the predictive accuracies of the two empirical SRK formulas in anterior chamber IOL implantation.

It must be noted that apart from the commonly used IOL power calculation formulas evaluated in this study various other formulas have recently been introduced including the Holladay ${ }^{18}$ and $S R K / T^{19}$ formulas, both of which combine the theoretical and empirical approaches.

\section{Material and methods}

All cases of anterior chamber IOL implantation performed at our hospital, either as a secondary procedure for aphakia or following rupture of the posterior capsule in intended extracapsular extraction, between January 1984 and January 1990 were reviewed. We excluded cases of combined trabeculectomy and anterior chamber IOL implantation, and also if best corrected postoperative visual acuity was $<6 / 12$ or if postoperative refraction data were incomplete. The 97 eyes with anterior chamber IOLs which met the inclusion criteria were studied to evaluate the predictive accuracies of the various IOL power calculation formulas.

All the implantations were performed by two surgeons using indentical surgical techniques. The anterior chamber lenses implanted were of the same style and made by a single manufacturer - Kelman Multiflex MT Series (Cilco).

IOL power was calculated from measurements of axial length and corneal curvature. Axial length was measured by applanation (A scan ultrasonography) using the Cilco Sonometrics Digicon. Corneal curvature was measured with a Topcon OM-4 keratometer. The software program within the ultrasound equipment was used to calculate the emmetropic IOL power and the predicted postoperative refraction for multiple IOL powers based on the SRK or SRK II formulas with the manufacturer recommended ' $A$ ' constant of $115 \cdot 3$. The actual power of the IOL implanted by the surgeon in each case depended on the refractive needs of the patient and the state of the lens and the refraction in the fellow eye. Postoperative refraction used in this study were carried out between 8 and 12 weeks postoperatively when spectacles were prescribed.

Each of two theoretical and two empirical formulas, with the respective manufacturer recommended constant ('A' constant or anterior chamber depth), was used to predict the postoperative refraction in each patient for the lens power implanted by the surgeon. The value (in dioptres) of the difference between the predicted postoperative refraction and the actual postoperative refraction (spherical equivalence in dioptres), termed the predictive error, was computed in each individual case, for the four formulas under evaluation.

The predictive accuracies of the four formulas evaluated were compared on the basis of mean 'absolute' predictive error and its standard deviation, the range of predictive errors, and the 
distribution of the predictive errors (percentage of cases with actual postoperative refraction within 1 or 2 dioptres respectively of predicted postoperative refraction).

In the second part of this study, the SRK and SRK II formulas were solved to derive the respective optimised ' $A$ ' constants based on measurements of axial length (in $\mathrm{mm}$ ), corneal curvature (in dioptres) and the actual postoperative refraction (spherical equivalence in dioptres). In addition we 'personalised' the SRK II formula by first grouping the eyes according to axial length ${ }^{10}$ into short eyes $(<22 \mathrm{~mm})$, long eyes $(\geqslant 24.5 \mathrm{~mm})$, and average eyes and then deriving optimal ' $A$ ' constants within each group.

During optimisation of the ' $A$ ' constants the following groups of eyes were excluded: obvious errors in axial length or corneal curvature measurement, refractive error due to IOL tilt or malposition, induced surgical astigmatism of $>2.5 \mathrm{D}$ cylinder, and any eye with a predictive error of $>2.5 \mathrm{D}$ in spherical equivalence. These eyes were however included when evaluating the predictive accuracies of the two SRK formulas.

The ' $A$ ' constants were optimised using the refraction factors (RFs) recommended with each formula - the SRK formula ${ }^{2}$ uses a refraction factor of 1.5 , while the SRK $\mathrm{II}^{3}$ uses 1.25 for emmetropic IOL $>14 \mathrm{D}$ and 1.0 for emmetropic $\mathrm{IOL} \leqslant 14 \mathrm{D}$. The inverse of this refraction factor indicates the amount of change in postoperative refraction that will result for each dioptre of IOL power above or below the IOL power required for emmetropia. The formulas evaluated were: (1) SRK formula with the manufacturer recommended ' $A$ ' constant, (2) SRK formula with the optimised 'A' constant, (3) SRK II formula with the manufacturer recommended ' $A$ ' constant, (4) SRK II formula with the optimised 'A' constant, and (5) the 'personalised' SRK II formula. Each of the above five formulas was used to predict the postoperative refraction and compute the predic-

Table 1 Predictive error (in dioptres) of the four formulas evaluated in eyes grouped according to axial length

\begin{tabular}{|c|c|c|c|}
\hline & $\operatorname{Mean}(S D)^{\star}$ & Range & $\begin{array}{l}p \text { value } \\
\text { vs } S R K \text { formula }\end{array}$ \\
\hline $\begin{array}{l}\text { Short eyes } \\
A L<22 m m(n=18) \\
\text { SRK } \\
\text { SRK II } \\
\text { Binkhorst II } \\
\text { Colenbrander-Hoffer }\end{array}$ & $\begin{array}{l}1.33(1.30) \\
1.47(0.88) \\
1.37(1.13) \\
1.44(0.95)\end{array}$ & $\begin{array}{l}-0.94-3 \cdot 69 \\
-1 \cdot 68-3 \cdot 20 \\
-1 \cdot 12-3.60 \\
-1.92-3 \cdot 20\end{array}$ & $\begin{array}{l}- \\
\text { NS } \\
\text { NS }\end{array}$ \\
\hline $\begin{array}{l}\text { Average eyes } \\
A L 22-24 \cdot 49 \mathrm{~mm}(n=51) \\
\text { SRK } \\
\text { SRK II } \\
\text { Binkhorst II } \\
\text { Colenbrander-Hoffer }\end{array}$ & $\begin{array}{l}1.22(1.05) \\
1.23(1.06) \\
1.48(1.13) \\
1.38(1.05)\end{array}$ & $\begin{array}{l}-1 \cdot 81-3 \cdot 42 \\
-2 \cdot 16-3 \cdot 52 \\
-1 \cdot 20-3.92 \\
-1 \cdot 76-3 \cdot 84\end{array}$ & $\begin{array}{l}- \\
\text { NS } \\
\text { NS }\end{array}$ \\
\hline $\begin{array}{l}\text { Long eyes } \\
A L \geqslant 24 \cdot 5 m m(n=28) \\
\text { SRK } \\
\text { SRK II } \\
\text { Binkhorst II } \\
\text { Colenbrander-Hoffer }\end{array}$ & $\begin{array}{l}0.82(0.58) \\
1.17(0.88) \\
1.54(0.94) \\
1.77(0.92)\end{array}$ & $\begin{array}{l}-2 \cdot 21-1 \cdot 34 \\
-2 \cdot 80-2 \cdot 50 \\
-1 \cdot 50-3 \cdot 50 \\
-1 \cdot 50-4 \cdot 00\end{array}$ & $\begin{array}{l}- \\
\text { NS } \\
<0.001 \\
<0.001\end{array}$ \\
\hline $\begin{array}{l}\text { All cases }(n=97) \\
\text { SRK } \\
\text { SRK II } \\
\text { Binkhorst II } \\
\text { Colenbrander-Hoffer }\end{array}$ & $\begin{array}{l}1.13(0.99) \\
1.25(0.99) \\
1.47(1.05) \\
1.50(0.99)\end{array}$ & $\begin{array}{l}-2 \cdot 21-3.69 \\
-2 \cdot 80-3.52 \\
-1.50-3.92 \\
-1.92-4.00\end{array}$ & $\begin{array}{l}- \\
\text { NS } \\
<0.05 \\
<0.01\end{array}$ \\
\hline
\end{tabular}

^ Mean (SD) of absolute predictive error

$\mathrm{AL}=$ axial length

$n=$ number of cases tive error in each individual case for the lens power implanted by the surgeon.

The predictive accuracies of the five formulas evaluated were compared on the basis of: mean absolute predictive error and its standard deviation, 'average' predictive error (taking into account the plus or minus signs of the predictive errors) and its standard deviation, and the distribution of the predictive errors (number of cases with $<1 \mathrm{D}$ or $<2 \mathrm{D}$ of predictive error).

\section{STATISTICAL ANALYSIS}

In both parts of this study the statistical significance of the differences in the predictive accuracies of the formulas evaluated was assessed using (i) standard error of the difference between means on the mean predictive error of the different formulas, and (ii) $\chi^{2}$ test on the number of cases with $<1 \mathrm{D}$ of predictive error.

\section{Results}

Table 1 shows the mean absolute predictive errors of each of the four formulas for anterior chamber IOL implantation in eyes of different axial lengths. There were 18 short eyes $(<22 \mathrm{~mm}), 28$ long eyes $(\geqslant 24.5 \mathrm{~mm})$, and 51 eyes of average axial length (22-24.49 mm). The SRK formula had the smallest mean predictive error overall. This was statistically significant when compared with the Binkhorst II $(p<0.05)$ and Colenbrander-Hoffer $(p<0.01)$ formulas but not with the SRK II formula $(p>0 \cdot 1)$. The SRK formula also had the smallest mean predictive error within the different subsets of eyes studied but this was not statistically significant except when compared with the Binkhorst II and Colenbrander-Hoffer formulas in long eyes $(p<0.001)$. The theoretical formulas had larger predictive errors than the empirical formulas in eyes of average and long axial lengths but were similar in short eyes.

The distribution of the predictive errors of the four formulas evaluated in eyes of different axial length groups is shown in Table 2 . The predictive errors are depicted as cumulative percentages within 1 dioptre and within 2 dioptres and as percentages over 3 dioptres for each of the various IOL power calculation formulas. The SRK formula had the largest percentage of cases within $1 \mathrm{D}$ of predicted postoperative refraction in short eyes $(67 \%)$, long eyes $(71 \%)$, and all cases (70\%). However none of the differences in Table 2 were statistically significant.

The manufacturer recommended ' $A$ ' constant with the SRK formula was $115 \cdot 3$ for the Kelman Multiflex style of anterior chamber IOL implanted in all the cases. After optimisation the ' $A$ ' constant was $116 \cdot 1$ for the SRK formula and $116 \cdot 2$ for the SRK II formula respectively.

The optimised ' $A$ ' constants for the personalised SRK II formula were 116.8 for short eyes, 116.3 for eyes of average axial length, and 115.6 for long eyes.

Table 3 shows the predictive errors of the various formulas in eyes of different axial lengths. After optimising the respective ' $A$ ' constants both the SRK and SRK II formulas showed a reduction in mean absolute predictive error and a 
Table 2 Distribution of predictive error of the four formulas in eyes grouped according to the axial length

\begin{tabular}{|c|c|c|c|c|}
\hline & $S R K$ & $S R K I I$ & Binkhorst II & Colenbrander-Hoffer \\
\hline $\begin{array}{l}\text { Short eyes } \\
A L<22 \mathrm{~mm}(n=18) \\
\star<1 \mathrm{D} \\
\star<2 \mathrm{D} \\
\dagger>3 \mathrm{D}\end{array}$ & $\begin{array}{r}67 \\
78 \\
6\end{array}$ & $\begin{array}{r}33 \\
67 \\
6\end{array}$ & $\begin{array}{r}56 \\
78 \\
6\end{array}$ & $\begin{array}{r}50 \\
78 \\
6\end{array}$ \\
\hline $\begin{array}{l}\text { Average eyes } \\
A L 22-24 \cdot 49 m m(n=51) \\
\star<1 \mathrm{D} \\
\star<2 \mathrm{D} \\
\dagger>3 \mathrm{D}\end{array}$ & $\begin{array}{r}71 \\
90 \\
2\end{array}$ & $\begin{array}{r}73 \\
92 \\
2\end{array}$ & $\begin{array}{r}65 \\
88 \\
4\end{array}$ & $\begin{array}{r}65 \\
86 \\
4\end{array}$ \\
\hline $\begin{array}{l}\text { Long eyes } \\
A L \geqslant 24 \cdot 5 m m(n=28) \\
\star<1 \mathrm{D} \\
\star<2 \mathrm{D} \\
\dagger>3 \mathrm{D}\end{array}$ & $\begin{array}{l}71 \\
93 \\
-\end{array}$ & $\begin{array}{l}64 \\
82 \\
-\end{array}$ & $\begin{array}{r}46 \\
82 \\
4\end{array}$ & $\begin{array}{r}43 \\
86 \\
4\end{array}$ \\
\hline $\begin{array}{l}\text { All cases }(n=97) \\
\star<1 \mathrm{D} \\
\star<2 \mathrm{D} \\
\dagger>3 \mathrm{D}\end{array}$ & $\begin{array}{r}70 \\
89 \\
2\end{array}$ & $\begin{array}{r}63 \\
85 \\
2\end{array}$ & $\begin{array}{r}58 \\
85 \\
4\end{array}$ & $\begin{array}{r}56 \\
82 \\
4\end{array}$ \\
\hline
\end{tabular}

$\mathrm{AL}=$ axial length

$n=$ number of cases

tendency for the mean 'average' predictive error to be closer to zero with one exception: in long eyes the mean 'average' predictive error of the SRK formula moved away from zero. The personalised SRK II formula had the lowest mean absolute predictive error and the closest to zero mean 'average' predictive error except in long eyes (Table 3). After optimisation of the ' $A$ ' constant the SRK formula $(\mathrm{p}<0.04)$, SRK II formula $(p<0.05)$, and the personalised SRK II formula $(p<0.03)$ showed a statistically significant reduction in the mean 'average' predictive error when all the eyes were considered.

Table 4 shows the cumulative percentages of cases with actual postoperative refraction within $1 \mathrm{D}$ and within $2 \mathrm{D}$ of the predicted postoperative refraction and also the percentage of eyes with more than $3 \mathrm{D}$ of predictive error for the five formulas evaluated. None of the differences were statistically significant.

\section{Discussion}

In this study of commonly used IOL power calculation formulas in anterior chamber IOL

Table 4 Distribution of predictive errors of the various

formulas evaluated in eyes grouped according to axial length

\begin{tabular}{|c|c|c|c|c|c|}
\hline & $S R K$ & $O p t S R K$ & $S R K I I$ & $O p t S R K I I$ & Pers SRK II \\
\hline $\begin{array}{l}\text { Short eyes } \\
A L<22 m m(n=1 \\
\star<1 \mathrm{D} \\
\star<2 \mathrm{D} \\
\dagger>3 \mathrm{D}\end{array}$ & $\begin{array}{r}67 \\
78 \\
6\end{array}$ & $\begin{array}{r}72 \\
94 \\
6\end{array}$ & $\begin{array}{r}33 \\
67 \\
6\end{array}$ & $\begin{array}{r}39 \\
72 \\
6\end{array}$ & $\begin{array}{l}61 \\
94 \\
-\end{array}$ \\
\hline $\begin{array}{l}\text { Average eyes } \\
A L 22-24 \cdot 49 \mathrm{~mm} \\
\star<1 \mathrm{D} \\
\star<2 \mathrm{D} \\
\dagger>3 \mathrm{D}\end{array}$ & $\begin{array}{r}71 \\
90 \\
2\end{array}$ & $\begin{array}{l}71 \\
90 \\
-\end{array}$ & $\begin{array}{r}73 \\
92 \\
2\end{array}$ & $\begin{array}{l}73 \\
92 \\
-\end{array}$ & $\begin{array}{l}75 \\
94 \\
-\end{array}$ \\
\hline $\begin{array}{l}\text { Long eyes } \\
A L \geqslant 24 \cdot 5 \mathrm{~mm}(n \\
\star<1 \mathrm{D} \\
\star<2 \mathrm{D} \\
\dagger>3 \mathrm{D}\end{array}$ & $\begin{array}{l}71 \\
93 \\
-\end{array}$ & $\begin{array}{r}79 \\
96 \\
4\end{array}$ & $\begin{array}{l}64 \\
82 \\
-\end{array}$ & $\begin{array}{r}75 \\
96 \\
4\end{array}$ & $\begin{array}{l}86 \\
96 \\
-\end{array}$ \\
\hline $\begin{array}{l}\text { All cases }(n=97) \\
\star<1 \mathrm{D} \\
\star<2 \mathrm{D} \\
\dagger>3 \mathrm{D}\end{array}$ & $\begin{array}{r}70 \\
89 \\
2\end{array}$ & $\begin{array}{r}73 \\
93 \\
2\end{array}$ & $\begin{array}{r}63 \\
85 \\
2\end{array}$ & $\begin{array}{r}67 \\
90 \\
2\end{array}$ & $\begin{array}{l}75 \\
95 \\
-\end{array}$ \\
\hline
\end{tabular}

$\mathrm{AL}=$ axial length

$n=$ number of cases

rcentage

tpercentage of all eyes
Table 3 Predictive errors of the formulas evaluated in eyes grouped according to axial length

\begin{tabular}{|c|c|c|}
\hline & $\begin{array}{l}\text { Predictive error (in D) } \\
\text { Average } \\
\text { Mean }(S D)\end{array}$ & $\begin{array}{l}\text { Absolute } \\
\text { Mean }(S D)\end{array}$ \\
\hline $\begin{array}{l}\text { Short eyes } \\
A L<22 m m(n=18) \\
\text { SRK } \\
\text { Optimised SRK } \\
\text { SRK II } \\
\text { Optimised SRK II } \\
\text { Personalised SRK II }\end{array}$ & $\begin{array}{r}1.10(1.53) \\
0.68(1.42) \\
0.51(1.71) \\
-0.37(1.63) \\
0.03(1.61)\end{array}$ & $\begin{array}{l}1.33(1.30) \\
1.23(1.04) \\
1.47(0.88) \\
1.39(0.77) \\
1.19(0.84)\end{array}$ \\
\hline $\begin{array}{l}\text { Average eyes } \\
\text { AL 22-24.49 } m m(n=51) \\
\text { SRK } \\
\text { Optimised SRK } \\
\text { SRK II } \\
\text { Optimised SRK II } \\
\text { Personalised SRK II }\end{array}$ & $\begin{array}{l}0.70(1.46) \\
0.26(1.51) \\
0.67(1.47) \\
0.19(1.50) \\
0.08(1.51)\end{array}$ & $\begin{array}{l}1 \cdot 22(1.05) \\
1 \cdot 19(0.81) \\
1 \cdot 23(1.06) \\
1 \cdot 17(0.83) \\
1 \cdot 16(0.80)\end{array}$ \\
\hline $\begin{array}{l}\text { Long eyes } \\
A L \geqslant 24 \cdot 5 m m(n=28) \\
\text { SRK } \\
\text { Optimised SRK } \\
\text { SRK II } \\
\text { Optimised SRK II } \\
\text { Personalised SRK II }\end{array}$ & $\begin{array}{r}-0.02(1.04) \\
-0.26(1.29) \\
0.50(1.41) \\
0.14(1.26) \\
0.28(1.28)\end{array}$ & $\begin{array}{l}0.82(0.58) \\
1.13(0.99) \\
1.17(0.88) \\
0.95(0.83) \\
0.85(0.81)\end{array}$ \\
\hline $\begin{array}{l}\text { All cases }(n=97) \\
\text { SRK } \\
\text { Optimised SRK } \\
\text { SRK II } \\
\text { Optimised SRK II } \\
\text { Personalised SRK II }\end{array}$ & $\begin{array}{l}0.57(1.40) \\
0.13(1.45) \\
0.59(1.47) \\
0.17(1.45) \\
0.11(1.44)\end{array}$ & $\begin{array}{l}1.13(0.99) \\
1.11(0.87) \\
1.25(0.99) \\
1.21(0.83) \\
1.08(0.81)\end{array}$ \\
\hline
\end{tabular}

$\mathrm{AL}=$ axial length

$n=$ number of cases

$\mathrm{SD}=$ standard deviation

implantation the predictive accuracy of the SRK

II formula was similar to that of the SRK formula and two theoretical formulas, Binkhorst II and Colenbrander-Hoffer. The SRK formula was similar to the two theoretical formulas in short and average eyes but was more accurate in all the eyes as a whole and in long eyes.

In Richards and Steen's report of anterior chamber IOLs, ${ }^{12}$ the Binkhorst II theoretical formula was more accurate than the SRK and SRK II empirical formulas. This conclusion is not supported by our findings. This may be because several factors affect the accuracy of the IOL power calculation formulas. These include the method of ocular biometry, the surgical technique, the type and style of IOL, the IOL manufacturer, and the axial length of the operated eye. ${ }^{11} 1320$ In view of this we recommend that each ophthalmic surgeon should select the most accurate formula for his/her own practice by comparing the performance of the various formulas in a sample of his/her own patients after standardising the factors that affect IOL power calculation.

The manufacturer recommended constants were used in this study since the aim was to evaluate the comparative performance of the various IOL power calculation formulas in anterior chamber IOLs. The use of optimised constants reportedly improves the accuracy of various IOL power calculation formulas in posterior chamber intraocular lenses. ${ }^{10111+1719}$ This result has not yet been demonstrated with anterior chamber IOLs.

In the second part of this study of anterior chamber implants we focused our attention on the empirical SRK formulas (SRK and SRK II) mainly because they are highly accurate, widely utilised, and their ' $A$ ' constants can be readily optimised unlike the constants used by the theoretical formulas. ${ }^{8-11} 13-1721-28$ 
We did not evaluate the recently developed SRK/T formula ${ }^{19}$ which is a combination of the empirical and theoretical approaches because (i) at present it is neither readily available nor widely used, (ii) it was not superior to the more commonly used SRK II formula except in eyes of axial length $>28.4 \mathrm{~mm},{ }^{19}$ and eyes of this axial length were not encountered in this study population.

The optimisation of the ' $A$ ' constants resulted in a statistically significant reduction in the mean 'average' predictive error, but there was no significant increase in percentage of cases within $1 \mathrm{D}$ of predictive error. This may be due to the relatively small number of eyes studied. Presently we are undertaking a larger study to determine if the observed statistically significant reduction in the mean 'average' predictive error after optimisation of the ' $A$ ' constant translates into a significant increase in predictive accuracy of the empirical SRK formulas in terms of the percentage of cases within $1 \mathrm{D}$ of predictive error.

We thank Sister A E Lewis for administrative help and M Lynch for help with the computerised data analysis.

1 Colenbrander MC. Calculation of the power of an iris clip lens for distant vision. Brf Ophthalmol 1973; 57: 735-40.

Fyodorov SN, Galin MA, Linksz A. Calculation of the optical power of intra-ocular lenses. Invest Ophthalmol Vis Sci 1975; 14: $615-8$.

3 Binkhorst CD. Dioptrienzahl Kunstlicher Augenlinsen. Klin Monatsbl Augenheilkd 1973; 162:354-61.

4 Retzlaff J. A new intra-ocular lens calculation formula. Am Intra-ocular Implant Soc $\mathcal{F} 1980 ; 6$ : 148-52.

5 Sanders DR, Kraff MC. Improvement of intra-ocular lens power calculation using empirical data. Am Intra-ocular Implant Soc F 1980; 6: 263-7.

6 Gills GP. Minimizing post-operative refractive error. Contact Intraocular Lens Med F 1980; 6: 56-9.

7 Sanders D, Retzlaff J, Kraff M, Kratz R. Comparison of the accuracy of the Binkhorst, Colenbrander and SRK implant power prediction formulae. Am Intra-ocular Implant Soc $\mathcal{F}$ $1 ; 7: 337-40$.

8 Binkhorst RD Intra-ocular lens calculation manual. A guide to the authors TI 58/59 IOL power module. 2nd ed. New York: Binkhorst, 981.

9 Hoffer KJ. Intra-ocular lens calculation: the problem of the short eye. Ophthalmic Surg 1981; 122: 269-72.

10 Sanders DR, Retzlaff J, Kraff MC Comparison of the SRK II formula and other second generation formulae. $\mathcal{F}$ Cataract Refract Surg 1988; 14: 136-41.

11 Dang MS, Sunder Raj P. SRK II formula in the calculation of intra-ocular lens power. Brf Ophthalmol 1989; 73: 823-6.

12 Richards SC Steen DW. Clinical evaluation of the Hollada and SRK II formulae. $\mathcal{F}$ Cataract Refract Surg 1990; 16: 71-

13 Richards SC, Olson RJ, Richards WL, Brostein RS, Hale PN. Clinical evaluation of six intra-ocular calculation formulae. Am Intra-ocular Implant Soc $\mathcal{F}$ 1985; 11: 153-8.

14 Tutton MK. Intra-ocular lens power calculation using the SRK formula: a clinical study. Trans Ophthalmol Soc UK $1986 ; 104: 675-80$.

15 Longstaff $S$. Factors affecting intra-ocular power calculations. Trans Ophthalmol Soc UK 1986; 105: 642-5.

16 Dang MS, Sunder Raj P. Calculation of the power of posterio chamber implants. Afro-Asian $\mathcal{F} O$ phthalmol (in press).

17 Sunder Raj P. Calculation of intra-ocular lens power. $f$ Cataract Refract Surg 1990; 16: 387-8.

18 Holladay JT, Praeger TC, Chandler TY, Musgrove KH. A three-part system for refining intra-ocular lens powe calculations. I Cataract Refract Surg 1988; 14:17-24.

19 Sanders DR Realarf JA Kract urg 1988, 14: 17-24. MG. Comparison of the SRK/T formula and othe theoretical and regression formulae. F Cataract Refract Surg 1990; 16: 341-6.

20 Halliday BL. Calculation of intra-ocular lens power - results in practice. Trans Ophthalmol Soc UK 1986; 105: 435-40.

1 Retzlaff J, Sanders DR, Kraff MC. A manual of implant powe calculation. Oregon: Medford, 1982.

22 Singh K, Sommer A, Jensen AD, Payne JW. Intra-ocular len power calculations. A practical evaluation in normal subjects at the Wilmer institute. Arch Ophthalmol 1987; 105: 1046

23 Percival P. Lens power calculation - is it necessary? Tran Ophthalmol Soc UK 1983; 103: 577-9.

24 Menezo JL, Chaques V, Harts $M$. The SRK regressio formula in calculating the dioptric power of the intra-ocula lens. Br $\mathcal{F}$ Ophthalmol 1984; 68: 235-7.

25 Lugo $M$. A simple BASIC computer program to individualize SRK formula. Arch Ophthalmol 1986; 104: 687 .

26 Singh M, Dahalan A. Significance of intra-ocular lens powe calculation. Brf Ophthalmol 1987; 71: 850-3.

27 Hope-Ross $M$, Mooney $D$. Intra-ocular lens power calculation. Eye 1988; 2: 367-9.

28 Gregory PTS, Esbester RM, Boase DL. Accuracy of routine intra-ocular lens power calculation in a district general hospital. Brf Ophthalmol 1989; 73: 57-60. 